\title{
Based on LabVIEW Remote Virtual Electronic Laboratory Design and Implementation
}

\author{
Yongyu Peng* and Kehong Zhang
}

School of Information \& Electrical Engineering, Zhejiang University City College, Hangzhou 310015, China

\begin{abstract}
This article is mainly aimed at the rapid development of remote virtual laboratory. This paper first analyzes programming tool of virtual laboratory and explains why LabVIEW is chosen. Then, introduce a detailed thought to make use of LabVIEW program (VI) feature that HTML webpage can be inserted conveniently; design remote virtual electrical and electronic laboratory software applicable to electrical and electronic experiment education in universities. With instances, explain the design process and effect. Finally, this paper shows that fast establishment of remote virtual laboratory by LabVIEW is both feasible and simple.
\end{abstract}

Keywords: Electrical and electronic education, LabVIEW, remote laboratory.

\section{INTRODUCTION}

In the internet age, teaching mode and learning style have changed tremendously. Web laboratories change character of courses [1], make laboratory exercises easier and give open access (from anyplace, anytime).

The most important contribution of modern remote education is that "teaching" and "learning" modes have changed fundamentally. That is to say, transform from centering on "teacher" and "classroom" to centering on "student". Students' autonomic learning has become a core concept in internet learning era.

Traditional content-oriented teaching approaches are being replaced by student-oriented ones. In agreement with the principles of constructivism, ICTs benefit from interactivity $[2]$.

\subsection{Goals}

Building of remote virtual electrical and electronic laboratories facilitates students' autonomic learning. Through virtual experiments, students can preview experimental contents, get to know experimental process and observe possible experimental phenomenon. Therefore, students will be easier and more confident at experimental classes and experimental teachers' workload will be reduced.

Virtual electrical and electronic laboratories are mainly used by beginners of electrical specialties in universities. Therefore, application interface and experimental content are simple and easy to operate; there are many experimental instructions.

For this reason, it is necessary to apply remote laboratories in teaching courses and experiments to avoid a decrease in the students motivation, feeling of loneliness, etc [3]. Virtual remote laboratories have 4 targets:

1. Increase experimental items. Expand students' scope of knowledge, covering digital circuit, analog circuit, electrotechnics, and circuit principles and so on. Make up the deficient breadth of experimental contents due to lack in experimental hours.

2. Boost students' experimental interests. Remote virtual experiments attach importance to visualization, interaction and interest, so students find funs in learning engineering courses and thus like electronics.

3. Facilitate teachers' teaching. PDF or PPT of traditional classroom teaching can demonstrate preset pictures or videos on computers, but it is very difficult to operate interactively. The application of remote virtual electrical and electronic experiments in teaching will resort to powerful functions of LabVIEW, demonstrate electrical and electronic experiments, and explain experimental operations during the interaction with virtual instruments.

4. Facilitate students' out-of-class learning. Through remote virtual electrical and electronic laboratories, students can preview experiments in advance, understand experimental principles and analyze experimental data.

At the same time, students can enjoy increased control over their learning environment, and prepare for laboratory periods by beginning the laboratories on-line before class by accessing pre-lab instruction and assignments on the web [4]. In the educational field, remote virtual laboratory have been introduced allowing the teachers to find innovative techniques to enhance the students' motivation and improve their education, information exchange between teacher and student through internet, information access from any part of the world without temporal constraints [5]. 
Table 1. Tool comparison.

\begin{tabular}{|c|c|c|c|}
\hline & Flash & Java & LabVIEW \\
\hline \hline Art design difficulty & C & C & A \\
\hline Programming difficulty & B & A & A \\
\hline Web publishing & A & A & A \\
\hline Function support & C & B & B \\
\hline
\end{tabular}

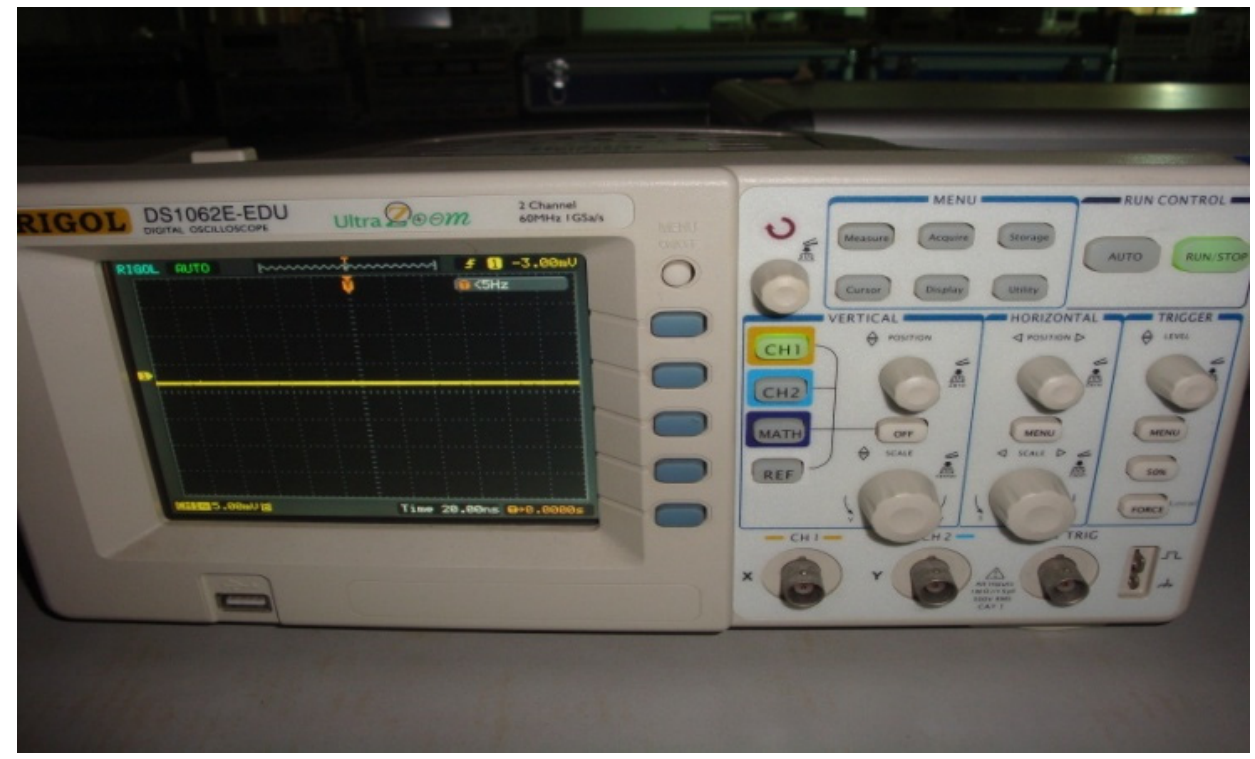

Fig. (1). Real oscilloscope.

\subsection{Design Tool}

In virtual electrical and electronic laboratories, three design tools were considered at the beginning, namely, Flash, Java and LabVIEW.

LabVIEW is a software product of National Instruments. It mainly applies to data collection, analysis and processing, automatic control, digital signal processing and virtual instrument. Its essential feature is "instrument virtualization".

Flash is an interactive vector diagram and Web animation standard launched by Macromedia Company and then acquired by Adobe Company. Flash is able to create beautiful webs.

Java is an object-oriented programming language that writes cross-platform application software, with excellent universality, effectiveness, platform portability and safety.

Choose the design tool from the following four aspects:

1. Art design difficulty. Flash aims at web design, so its animation effect is comparable to films. However, beautiful interactive effect requires powerful support from art design. A very realistic problem is that personnel in virtual laboratory project are electrical teachers in universities-without specialty of fine arts, it is difficult for them to create perfect effects with Flash. Java also requires high art design level. LabVIEW is especially applicable to circuit simulation, industrial control and instrument interface design.
2. Programming difficulty. Virtual experiments are realized through programming. Flash supports scripting language, which isn't powerful. Programming of virtual instruments is very inconvenient. As an effective programming language, Java realizes virtual experiments easily. LabVIEW, it has been shown that this graphical icon programming approach is a very effective learning method for many students. This software is an effective teaching and learning tool. LabVIEW has radically changed many aspects of measurement and automation industry [6].

3. Regarding web publishing. JAVA and Flash have been widely used in the internet, while LabVIEW supports independent operation of client side, with the installation of large client side support software.

4. Library. Virtual electrical and electronic laboratories need to display and process digital and analog signals, and need powerful support from class library. In this aspect, Flash is completely zero. JAVA owns a few third-party signal processing class library; this function of LabVIEW is the most powerful.

\section{Comparison is shown in Table $\mathbf{1 .}$}

Fig. (1) shows the appearance of a real oscilloscope. The following Fig. (2) is a virtual oscilloscope interface produced by LabVIEW8.6. Please pay attention to interface design. The author without specialty of fine arts only resorted to front panel control of LabVIEW and completed it within 1 hour. 


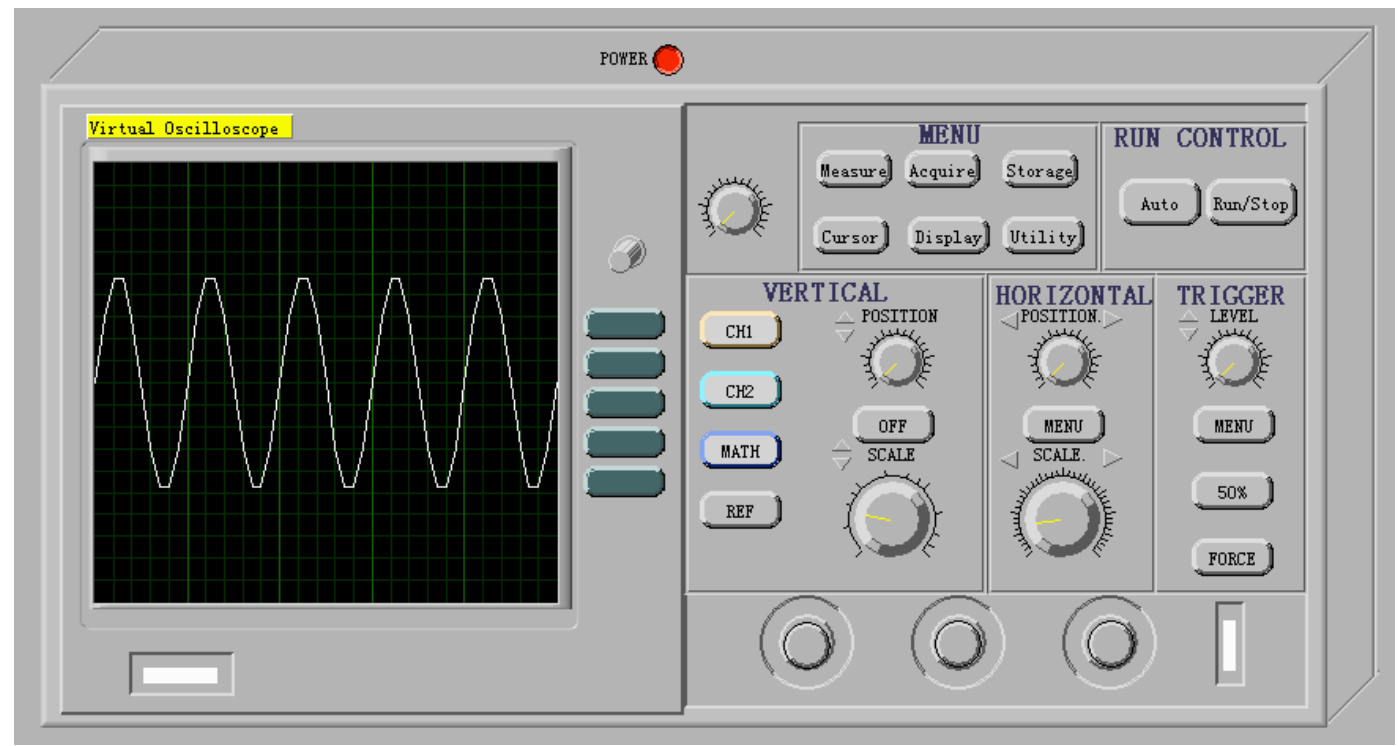

Fig. (2). Virtual oscilloscope.

Choosing correct design tool LabVIEW8.6 ensures quick and successful completion of the project.

\subsection{Course Unit and Outline}

Remote virtual electrical and electronic laboratory is a set of remote virtual laboratory platform, including 35 small virtual experiments in four parts: "digital circuit", "analog circuit", "circuit principle" and "instrument use".

1. Digital circuit experiment module consists of 14 small virtual experiments, such as "one-digit full adder", "fourdigit carry look-ahead full adder ", etc.

2. Analog circuit experiment module consists of 13 small virtual experiments: such as "diode direct current test circuit", “operational amplifier", etc.

3. Electrical experiment module consists of 5 small virtual experiments such as "volt-ampere characteristics of linear resistance", etc.

4. Instrument use module consists of 3 small virtual experiments such as. "Digital oscilloscope", "Function generator", etc.

\section{DESIGN METHOD AND INSTANCE}

\subsection{Overall Design Method}

Small virtual experiments are designed according to the following cyclic graph, shown as Fig. (3) Design thought refers to "waterfall model" with 7 steps:

Step 1: analysis phase. According to electrical and electronic experiment teaching requirements, analyze and define needs.

Step 2: definition phase. Through circuit experiment and Multisim simulation, analyze the experimental process, collect experimental data and record experimental phenomenon.

Step 3: modeling phase. Extract mathematic model from experimental phenomenon and data, define input-output relation and build corresponding simulation mode.

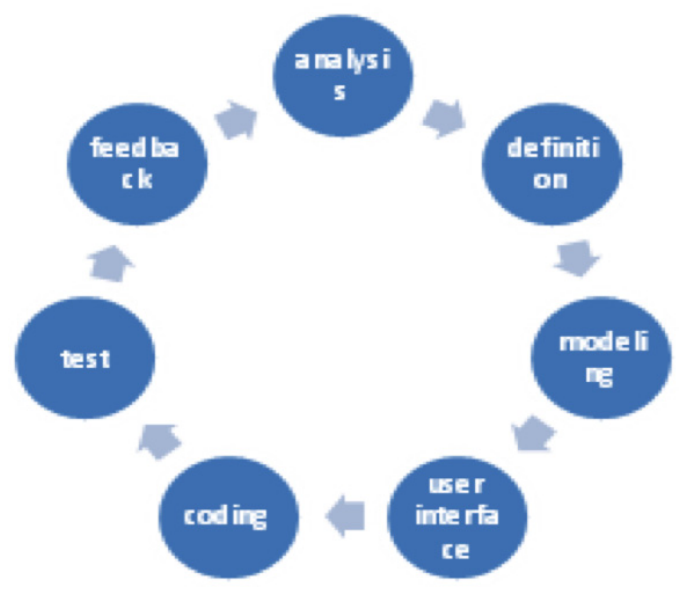

Fig. (3). Design thought.

Step 4: user interface phase. According to needs and experimental phenomenon, arrange input and output controls, define user interface and design front panel.

Step 5: coding phase. According to simulation model, complete the program chart of virtual experiment, test and release.

Step 6: test phase. Test and apply it to experimental teaching.

Step 7: feedback phase. According to students' use, revise virtual experimental requirements; redefine needs.

\subsection{Instance Illustration}

There are four types of small virtual experiments in remote virtual laboratory: demonstration and operation type virtual experiment, to dynamically demonstrate experimental operations; virtual experiment inspiring learning interest, to help student learn through games; data analysis and visualized virtual experiment, to help students observe and analyze experimental phenomenon; instrument use virtual experiment. 


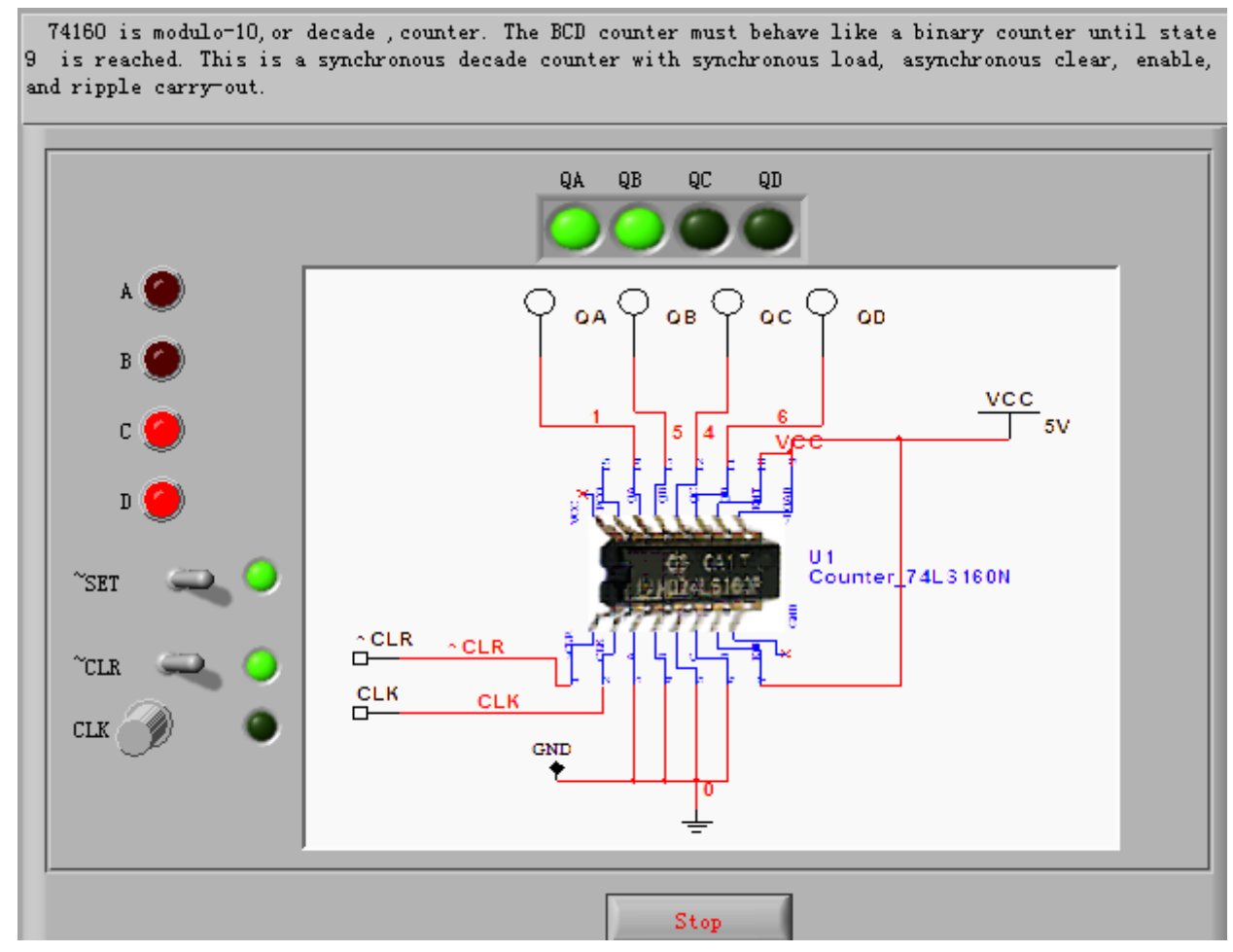

Fig. (4). Decimal counter based on 74LS160.

\subsubsection{Demonstration and Operation Type Virtual Experi- ment}

Based on 74LS160 decimal counter, operation interface is shown in Fig. (4). Through virtual decimal counter, students can input buttons of operation control and understand concepts such as zero clearing and setting, which are difficult for beginners.

1) Illustration: belonging to medium scale integrated circuit, $74 \mathrm{HC} 160$ is a decimal edge synchronous counter. $\sim$ CLR is zero clearing end; CLK is clock input end; ENP and ENT are working state control; LOAD presets digital control end; A, B, C and D are data input ends; RCO is carry bit output end; QA, QB, QC and QD are counter output ends.

To design a counter based on 74LS160/161 series components is an indispensable part of digital circuit teaching in most universities at present.

Circuit diagram in Fig. (6) comes from NI Multisim11. During design phase, the virtual experiment planned to use real object diagram, but found after test that students hardly understand circuit connection on real object diagram.

Multisim11 is common circuit simulation software and is highly accepted by students. Therefore, circuit diagram is drawn in Multisim11 and its screenshot is used during virtual instrument design.

2) Definition: input and output requirement: virtual decimal counter, input end: clock CLK, zero clearing

$\sim$ CLR; output: QA, QB, QC and QD. After definition, design the front panel according to input and output.

3) Coding: formula node of LabVIEW is applied to the design, so as to realize design easily, as is shown in Fig. (5).

\subsubsection{Virtual Experiment for Inspiring Learning Interest}

Virtual game design based on $74 \mathrm{HC} 153$ data selector. Operation interface is shown in Fig. (6).

1) Illustration: during multiplex data transfer, the circuit that can choose any one line according to needs is called data selector.74HC153 is 1 -of-4 data selector. If we need to choose one data from one group of alternative input data during digital signal transfer, we shall use data selector.

$74 \mathrm{HC} 153$ contains two 1-of-4 data selectors. They have a common address input end, but data input end and data output end are independent. By giving different address code (A and B status), they can choose one from 4 input data and send it to output end Y. $\sim 1 \mathrm{G}$ and $\sim 2 \mathrm{G}$ are additional control ends.

2) Definition: realize virtual experiment of 1-of-4 data selector. Twelve Chinese zodiac signs pass according to preset marshalling sequence and those in the right go first. Control the following address codes A and B; control the port $\sim 1 \mathrm{G}$. One group of four zodiac signs from input end corresponds to four channels of data selector. When $\sim 1 \mathrm{G}$ is at a low electrical level, AB $(00,01,11,11->0,1,2,3)$ correspond to zodiac signs in the channel, so correct zodiac signs will be released. Please note: since $74 \mathrm{HC} 153$ is a combinational logic circuit, when input changes, the output will change at once. Therefore, it is necessary to use additional control end $\sim 1 \mathrm{G}$ (the change can be valid only when additional control end at a low electrical level).

Input and output requirements: three input ends: $\mathrm{A}, \mathrm{B}$, $\sim 1 \mathrm{G}$. Output: passing zodiac signs, arranged zodiac signs, time used and intelligence level. 


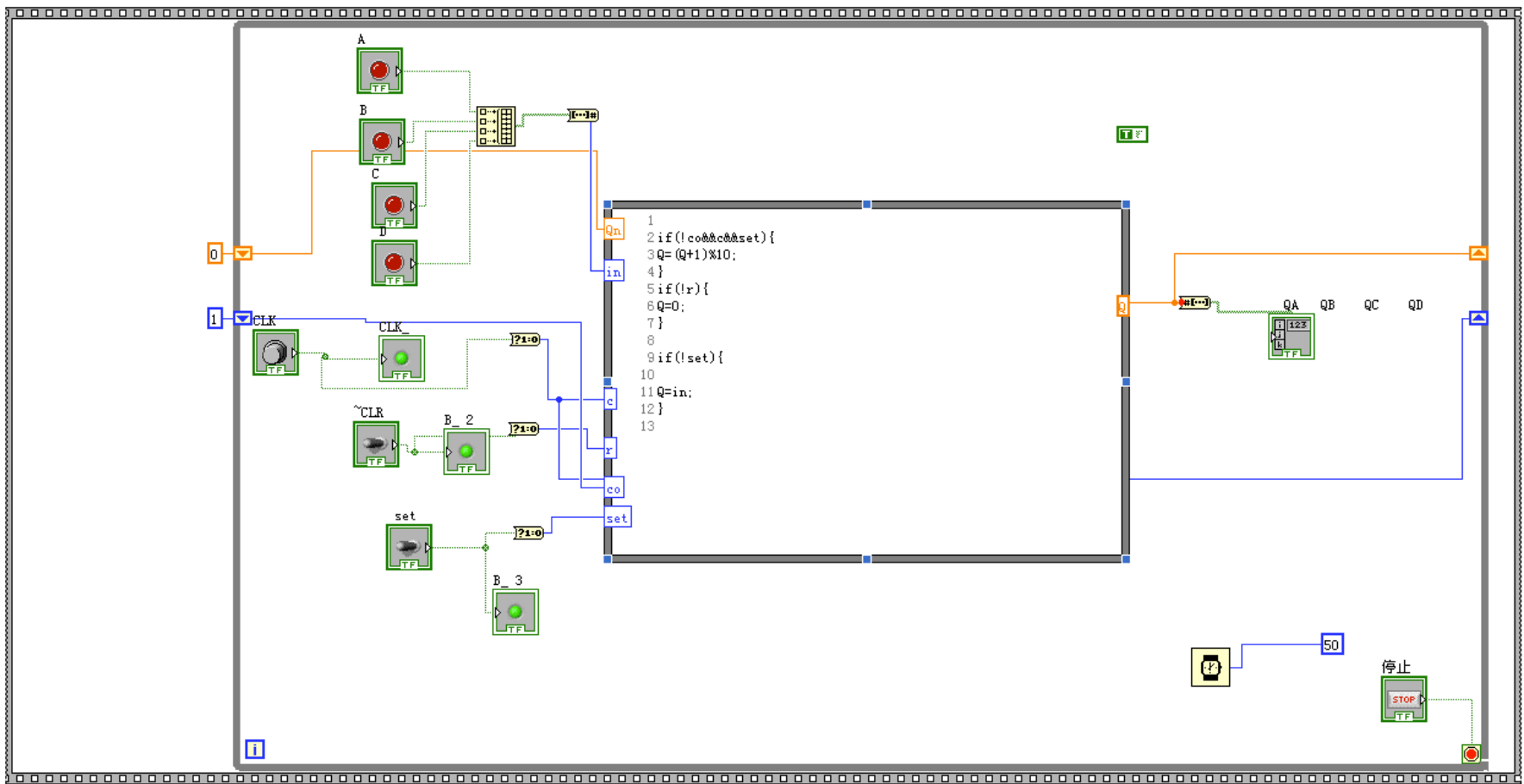

Fig. (5). Program char.

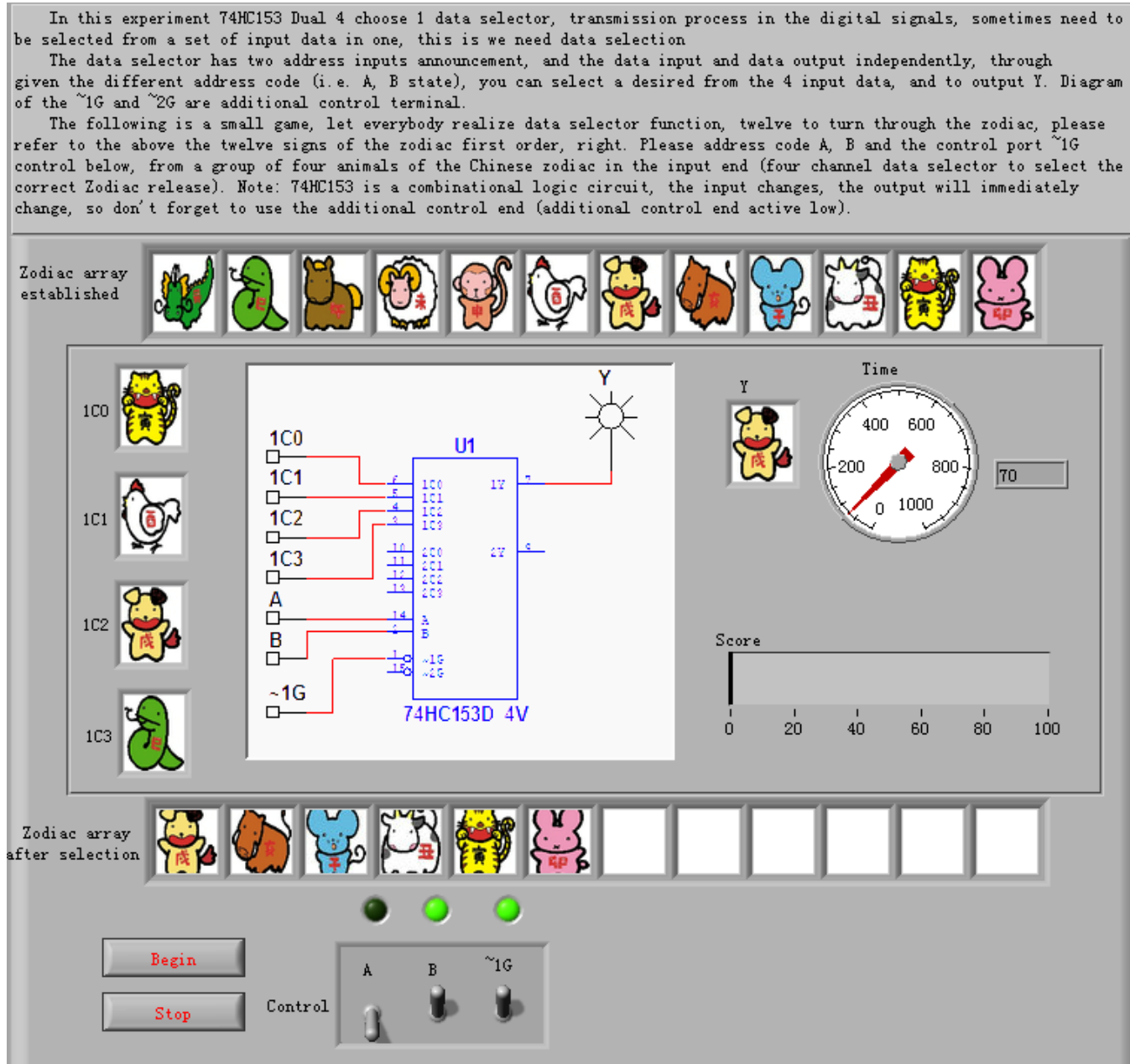

Fig. (6). Game operation interface of data selector. 


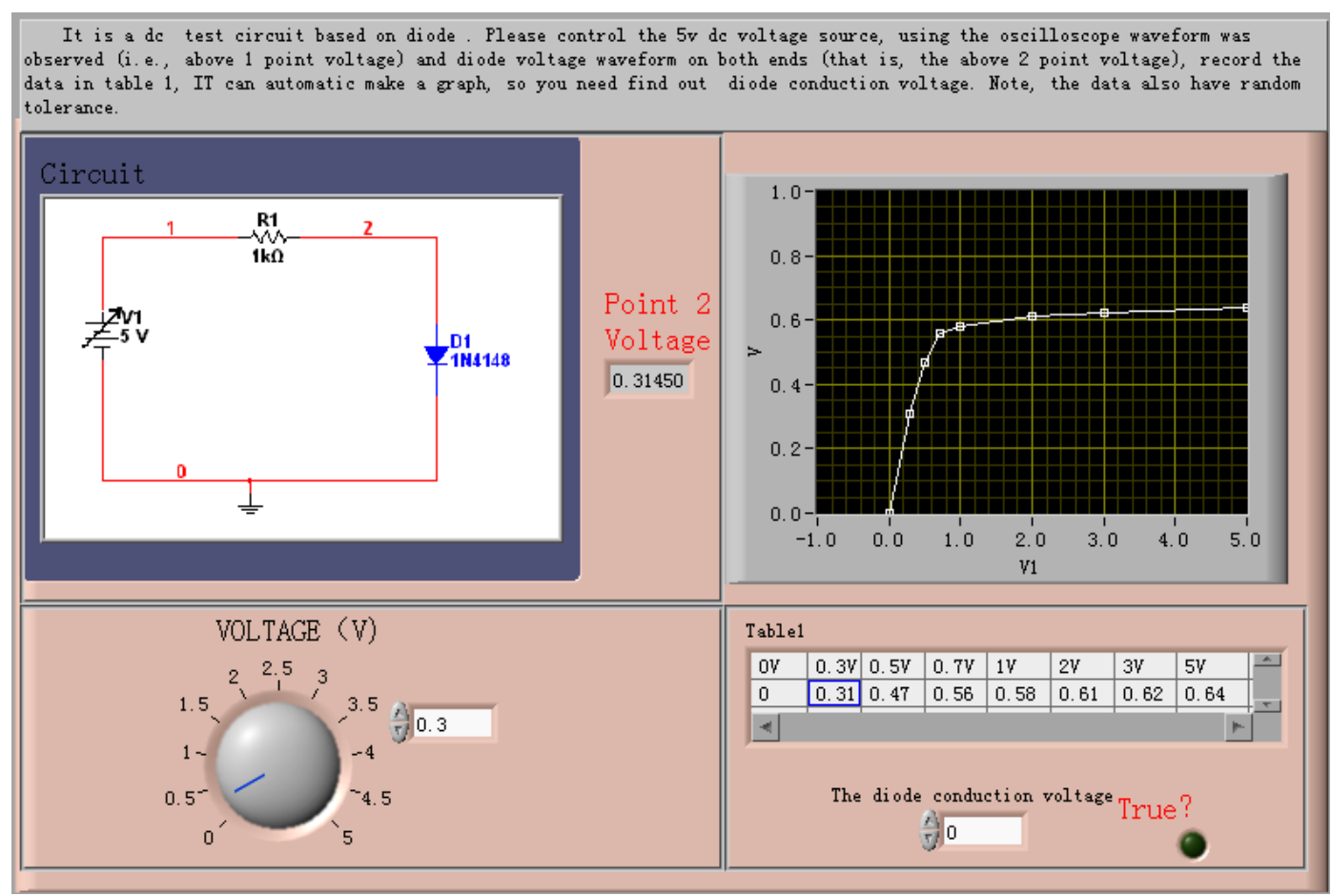

Fig. (7). Diode DC test circuit.

3) Coding: on the whole, the program adopts sequential structure, initializes the array of twelve Chinese zodiac signs, produces 4 random numbers and sends them into waiting array. Through LabVIEW timeout event, read input data every $10 \mathrm{mS}$, send into display array and compare it with correct array.

Main structure of this program adopts event structure of LabVIEW. Its working principle is similar to case structure of built-in notice function or event response function of VB. Event structure contains many branches, and each branch is an independent event processing program. Event structure may be time-out when waiting for event notice; in this case, specific time-out brand will be executed. This design mainly adopts two event branches: wait time-out event and stop press event.

This program is mainly realized through event structure of LabVIEW. After initialization, monitor input event and start the game.

\subsubsection{Data Analysis and Visualized Virtual Experiment}

Operation interface of virtual experiment design proposal of diode DC test circuit is shown in Fig. (7).

1) Illustration: diode $\mathrm{DC}$ test circuit: adjust $5 \mathrm{~V}$ adjustable DC voltage source, use voltmeter to observe voltage waveform at both ends of diode, record data in the table, produce curve chart automatically and then analyze it. Break-over voltage of diode can be judged from curve chart.

For example, computer simulations allow students to decide in situ the correct values to obtain and visualize certain physical phenomena [7], and students can record data, observe the waveform, analyze and record break-over voltage. After record, the system will validate its correctness automatically.
2) Definition: Input: voltage value; output: input voltage and diode voltage characteristic diagram data, input voltage and diode voltage characteristic diagram waveform, diode break-over voltage; whether diode break-over voltage is correct or not.

3) Coding: by defining the loop structure, set output and input; through formula node, complete the design according to (1) and (2).

\subsubsection{Instrument Virtual Experiment}

Virtual experiment interface of virtual function generator is shown as Fig. (8).

1) Illustration: digital signal generator is a circuit experimental instrument. To explain digital signal generator, teachers often let students watch operation video or demonstrate it. By watching video, students only sequentially observe the use method of digital signal generator. By teachers' demonstration, students can see the interaction between teachers and instrument, but cannot operate and validate it at once. Without teachers' guidance, when using digital signal generator for the first time, students' operation level is bad; they don't know its button function and their questions cannot be answered immediately.

Virtual experiment of digital signal generator is designed by reference to the interface of a real digital signal generator and its button function. Therefore, students can operate virtual signal generator outside laboratories, and get to know its button function and use method.

2) Definition: list and explain every pushbutton and rotary knob function of digital signal generator. The functions of digital signal generator are realized through event structure and "signal processing" - > "waveform generation" 



Fig. (8). Virtual function generator.

module in LabVIEW. Add two waveform control widgets; students will see the real-time effects.

\section{CONCLUSION}

Through rich control widget resources at front panel of LabVIEW, complete the interfaces of all kinds of instruments vividly; relying on powerful signal processing and simulation function library of LabVIEW, process many types of waveforms smoothly; through independent remote laboratory structure of LabVIEW client side, through VI that is released in LabVIEW, insert webpage and complete remote access. For university teachers, virtual laboratory turns into a project that can be realized quickly and completed easily. It is in these roles that the virtual instrumentation lab provides outstanding productivity gains [8].

Electrical and Electronic Laboratory of Zhejiang University City College has built a remote virtual electrical and electronic laboratory, which helps students to study, facilitates students linking theory with practice, expands students' thoughts and enhances students' learning interest. Moreover, inspire students' enthusiasm in autonomous learning, impel students to take part in practice and enhance innovative awareness. In one word, favorable teaching effect has been realized.

Of all students surveyed, $88.2 \%$ indicated that they liked remote virtual experiment [9].

Remote virtual electrical and electronic laboratory has been highly recognized in and out of the college. Remote virtual electrical and electronic laboratory has won the third prize of University Multi-media Courseware Appraisal held by Education Technology Center of China Zhejiang Province Education Department and Provincial Higher Education Association.
LabVIEW is very suitable to be used in higher education due to its beautiful graphic interface, powerful signal collection and processing function.

\section{CONFLICT OF INTEREST}

The authors confirm that this article content has no conflict of interest.

\section{ACKNOWLEDGEMENTS}

This paper belongs to the project of the "2012 Class Teaching Reform of Zhejiang University City College", No. KG1204.

\section{REFERENCES}

[1] M. Stefanovic, V. Cvijetkovic, M. Matijevic, and V. Simic, A Lab$V I E W$-based remote laboratory experiments for control engineering education, Comput Appl Eng Educ, 19 (2011), pp. 538-549.

[2] T. Duffy and K. Jonassen, Constructivism and the technology of instruction, Lawrence Erlbaum Associates, Hilsdale, New Jersey, 1992.

[3] J. Sa'nchez, Un nuevo enfoque metodolo'gico para la enseñanza a distancia de asignaturas experimentales: ana'lisis, diseño y desarrollo de un laboratorio virtual y remoto para el estudio de la Automa'tica a trave's de Internet. PhD Thesis, UNED, Spain, 2001.

[4] R. M. Powell, H. Anderson, J. van der Spiegel, and D. P. Pope, Using web-based technology in laboratory instruction to reduce costs, Comput Appl Eng Educ, 10 (2002), pp. 204-214.

[5] J. L. Guzman, M. Berenguel, F. Rodriguez, and S. Dormido, Webbased remote control laboratory using a greenhouse scale model, Comput Appl Eng Educ,13 (2005), pp.111-124.

[6] P. J. Moriarty, B. L. Gallagher, C. J. Mellor, and R. R. Baines, Graphical computing in the undergraduate laboratory: Teaching and interfacing with LabVIEW, Am J Phys 71 (2003), pp.10621074.

[7] A. Vidaurre, J. Riera, M. H. Jime'nez, and J. A. Monsoriu, Contribution of simulation in visualizing physics processes, Comput Appl Eng Educ, 10 (2002),pp.45-49. 
[8] W arren D. Smith, Ramon Berguer, and Robert G. Loeb, Virtual Instrumentation for Human Factors Studies in Surgery and Anesthesia,Laboratory Robotics and Automation, 10(1998),pp.99-105.
[9] Yongyu Peng, Junyan Peng. Application of a web-based remote virtual laboratory on innovative teaching of electronic circuits, Int. J. Cont. Engineering Education and Life-Long Learning, 22(2012), pp. $257-261$.

Received: September 16, 2014

(C) Peng and Zhang; Licensee Bentham Open

This is an open access article licensed under the terms of the Creative Commons Attribution Non-Commercial License (http://creativecommons.org/licenses/by-nc/3.0/) which permits unrestricted, non-commercial use, distribution and reproduction in any medium, provided the work is properly cited. 